I dent i f i cat i on, char act er i zat i on and for ensi $\mathrm{c}$ appl i cat i on of novel Y-STRs

\begin{tabular}{|l|l|}
\hline 著者 & I I DA Rei ko, K SH Koi chi ro \\
\hline $\begin{array}{l}\text { j our nal or } \\
\text { publ i cat i on t i t l e }\end{array}$ & Legal Nedi ci ne \\
\hline vol une & 7 \\
\hline number & 4 \\
\hline page range & $255-258$ \\
\hline year & $2005-07$ \\
\hline URL & ht t p: //hdl . handl e. net /10098/1183 \\
\hline
\end{tabular}




\section{Identification, characterization and forensic application of novel Y-STRs}

Reiko Iida $^{\mathrm{a},}{ }^{*}$, Koichiro Kishi $^{\mathrm{b}}$

${ }^{\mathrm{a}}$ Department of Forensic Medicine, Faculty of Medical Sciences, University of Fukui, Fukui 910-1193, Japan.

${ }^{b}$ Department of Legal Medicine and Molecular Genetics, Gunma University Graduate School of Medicine, Gunma 371-8511, Japan.

*Corresponding author. Tel.: +81-776-61-8340; fax.: +81-776-61-8108.

E-mail address: ireiko@fmsrsa.fukui-med.ac.jp (R.Iida). 


\begin{abstract}
Y-chromosomal polymorphic STRs are a powerful tool for forensic and evolutionary studies. Within the last decade, a series of Y-STR systems have been developed and demonstrated to be suitable for a variety of forensic applications including sexual assault cases and paternity testing. This review describes our recent studies on novel male-specific Y-STRs, involving identification, development of a multiplex-PCR system, population study and forensic application.
\end{abstract}

Keywords: Forensic science; Y chromosome; Short tandem repeat; Multiplex polymerase chain reaction; Population study; Stains 


\section{Introduction}

Among human chromosomes, the $\mathrm{Y}$ chromosome is unique in that most of it, excluding the pseudoautosomal region, does not participate in meiotic recombination and is inherited unaltered from father to son $[1,2]$. For this reason, analyses of human Y-linked polymorphic markers have been proposed as highly helpful tools for tracing human migration and evolution through male lineage as well as for forensic studies. Within the last decade, it has been demonstrated that these Y-specific markers, especially highly polymorphic Y-specific short tandem repeats (STRs), are suitable for forensic applications including cases of sexual assault and paternity cases where the putative father or other relatives are lacking, [3-5] and a series of Y-STR multiplex systems have been developed [6-10]. Of the various Y-STRs systems described so far, that consisting of nine loci - DYS19, DYS390, DYS391, DYS392, DYS393, DYS389I/II, and DYS385I/II - is best characterized and the haplotype data are continuously available online (Y-STR Haplotype Reference Database; http://www.ystr.org).

Recently, we have identified five additional and novel male-specific and polymorphic Y-STRs through a search of sequence database information and developed a multiplex system consisting of these STRs. In this article, we focus on our recent studies of these Y-STRs - DYS 441, DYS442, DYS443, DYS444 and DYS445 including identification, characterization and haplotype analysis, development of a multiplex-PCR system and forensic application .

\section{Identification of male-specific and polymorphic Y-STRs}

The Y chromosome consists of three regions: two pseudoautosomal regions (PARs) located on the most distal short arm (PAR1) and at the tip of the long arm (PAR2), a heterochromatic region, and the reminder of the chromosome (the non-recombining region, NRY)(Fig. 1). During male meiosis, the PAR1 and sometimes the PAR2 
undergo pairing and meiotic exchange with the $\mathrm{X}$ chromosome [11]. The heterochromatic region is composed of highly repeated DNA families (DYZ1 and DYZ2) and considerable individual variation exists with regard to its length. The Y-STRs that are suitable for forensic application lie within the NRY since this region is transmitted unaltered from father to son. However, the NRY contains many blocks of $\mathrm{X}-\mathrm{Y}$ homologous or $\mathrm{Y}$-autosome homologous sequences [2], and thus these regions must be excluded for male-specific identification.

As a first step to identify novel male-specific and polymorphic Y-STRs, sequence database information (http://www2.ebi.ac.uk/genomes/mot/) was screened for DNA sequences on the $\mathrm{Y}$ chromosome that had been mapped in proximity to $\mathrm{Y}$-specific regions within the NRY, and tetranucleotide microsatellites containing a stretch of nine or more repeat units were selected. After designing PCR primers and optimizing the PCR conditions for specific amplification of these microsatellites, male-specificity, existence of polymorphism and a regular mode of inheritance were tested by amplifying female DNA samples as negative controls, by analyzing the length of PCR products amplified from more than ten male DNA samples, and by analyzing father/son combinations from routine paternity cases, respectively $[12,13]$. Some of the microsatellites we located from the database were male-specific but not polymorphic, at least in the Japanese population, and therefore these STRs were excluded from our system. The positions of the five novel male-specific and polymorphic Y-STRs on the Y chromosome which we identified are shown in Fig. 1.

\section{Development of a multiplex PCR system}

In order to utilize these STRs more availably in real forensic casework, a sensitive and simultaneous typing method using a single PCR and electrophoretic run has been anticipated, and therefore we developed a new multiplex PCR system consisting of these five STRs. In certain situations such as cases involving old stains or highly 
decomposed body remains, it has been difficult to obtain reliable DNA typing results because of the drastically reduced yield of PCR products larger than $350 \mathrm{bp}$.

Accordingly, to increase the probability of obtaining a DNA typing result from aged materials, some of the primers were re-designed so that the sizes of the all PCR products were less than $350 \mathrm{bp}$.

The optimum PCR conditions including cycle conditions and the components of the PCR reaction mixture were examined for correct typing of the five STRs [14, 15]. Particularly, modification of the following conditions was effective for attaining clear electropherograms. (1) PCR cycling conditions: the optimum annealing temperature was determined so that non-specific peaks disappeared and the amplification efficiency was maximal; presence of split peaks resulting from addition of incomplete extra adenine nucleotide to the 3 ' end of the amplified fragment was drastically reduced by increasing the final extension time to $50 \mathrm{~min}$ to promote adenine nucleotide addition. (2) Contents of the PCR reaction mixture: absence of PCR products for DYS441 and DYS442 was improved by addition of ammonium sulfate; the optimum concentrations of the primers were determined to keep each of the five signal intensities at the same level.

Details of our developed and improved multiplex PCR system have been presented in our previous paper [15].

\section{Population study}

A population study of 340 unrelated Japanese males detected 7, 5, 6, 5 and 4 alleles in the DYS441 DYS442, DYS443, DYS444 and DYS445 systems, respectively, yielding 122 DYS441/ DYS442/DYS443/DYS444/DYS445 haplotypes. STR diversities were calculated to be 0.73 (DYS441), 0.50 (DYS442), 0.68 (DYS443), 0.57 (DYS444) and 0.54 (DYS445), and the haplotype diversity was 0.97 [15]. 
Recently, other groups performed population studies on these five Y-STR systems in Caucasian, African American and Chinese Han populations (Figs. 2 and 3).

Comparative study showed that the allelic distributions and STR diversities of these loci differed significantly among these populations and that some alleles were characteristic of the specific ethic groups (e.g. African American: allele 17 of DYS443).

\section{Forensic application}

Under the conditions determined for the multiplex PCR analysis, no signal was detected in any of the DNA samples (10-50 ng) from females. When much higher amounts of female DNA (100-250 ng) were used, several non-specific signals were detected, but these did not interfere with the correct typing of male samples because they lay outside the range within which the specific signals appeared. For the correct typing of five STRs, only 50 pg male DNA per $10 \mu$ reaction volume was required, suggesting that this multiplex PCR system is practical and useful for real forensic casework.

In forensic examination, most blood or semen samples are encountered in the form of stains. They are not always fresh and uncontaminated but sometimes aged or mixed with body fluids from others. Therefore, we investigated the possibility of typing from blood or semen stains stored for an extended period at room temperature $[14,15]$. All blood stains stored for 7 years were typed correctly, but typing of DYS443 and DYS444 was difficult from samples stored for twelve years. The amount of each blood stain required for typing was equivalent to $0.2-0.3 \mu \mathrm{l}$ of blood. In the case of semen stains, all stains stored for two weeks, seven years and eleven years were typed correctly, indicating that DNAs contained in semen stains are stable beyond expectation and the possibility of typing from semen stains is considerably higher than that from blood stains if they are stored under the same conditions. The amount of each semen stain required for typing was equivalent to $0.03-0.23 \mu 1$ of semen. Semen stains are often 
encountered as mixtures with vaginal secretion, and therefore this multiplex PCR system is advantageous for seminal individualization in cases of sex crime.

\section{Conclusion}

In this review, we have described a series of studies on five novel male-specific Y-STRs, involving identification, development of a multiplex-PCR system, population study and forensic application, and showed that this system is sufficiently practical for paternity testing, sex crime and personal identification from aged or decomposed male DNA samples. More recently, other novel Y-STRs and multiplex systems consisting of novel or preexisting Y-STRs have been reported $[18,19]$. It is expected that more data on population distribution or forensic application will be accumulated in the near future and that more accurate identification will be feasible.

\section{Acknowledgements}

We would like to thank Erin Hanson and Jack Ballantyne (University of Central Florida) for contributing unpublished population data. This work was supported in part by Grants-in-Aid from Japan Society for the Promotion of Science (16209023 to K. K.).

\section{References}

[1] Jobling MA, Tyler-Smith C. Fathers and sons: the Y chromosome and human evolution. Trends Genet 1995;11:449-56.

[2] Jobling MA, Tyler-Smith C. New uses for new haplotypes the human Y chromosome, disease and selection. Trends Genet 2000;16:356-62.

[3] Roewer L, Epplen JT. Rapid and sensitive typing of forensic stains by PCR 
amplification of polymorphic simple repeat sequences in case work. Forensic Sci Int 1992;53:163-71.

[4] Jobling MA, Pandya A, Tyler-Smith C. The Y chromosome in forensic analysis and paternity testing. Int J Legal Med 1997;110:118-24.

[5] Prinz M, Boll K, Baum H, Shaler B. Multiplexing of Y chromosome specific STRs and performance for mixed samples. Forensic Sci Int 1997;85:209-18.

[6] Butler JM, Schoske R, Vallone PM, Kline MC, Redd AJ, Hammer MF. A novel multiplex for simultaneous amplification of $20 \mathrm{Y}$ chromosome STR markers. Forensic Sci Int 2002;129:10-24.

[7] Sinha SK, Budowle B, Arcot SS, Richey SL, Chakrabor R, Jones MD, Wojtkiewicz PW, Schoenbauer DA, Gross AM, Sinha SK, Shewale JG. Development and validation of a multiplexed Y-chromosome STR genotyping system, Y-PLEX 6, for forensic casework. J Forensic Sci 2003;48:93-103.

[8] Hall A, Ballantyne J. The development of an 18-locus Y-STR system for forensic casework. Anal Bioanal Chem 2003;376:1234-46.

[9] Schoske R, Vallone PM, Kline MC, Redman JW, Butler JM. High-throughput Y-STR typing of U.S. populations with 27 regions of the Y chromosome using two multiplex PCR assays. Forensic Sci Int 2004;139:107-21.

[10] Hanson EK, Ballantyne J. A highly discriminating 21 locus Y-STR "megaplex" system designed to augment the minimal haplotype loci for forensic casework. J Forensic Sci 2004;49:40-51.

[11] Miller OJ, Therman E. Human Chromosomes. New York: Springer-Verlag, 2001. pp. $255-66$.

[12] Iida R, Tsubota E, Matsuki T. Identification and characterization of two novel human polymorphic STRs on the Y chromosome. Int J Legal Med 2001;115: 54-6.

[13] Iida R, Tsubota E, Sawazaki K, Masuyama M, Matsuki T, Yasuda T, Kishi K. Characterization and haplotype analysis of the polymorphic Y-STRs DYS443, 
DYS444 and DYS445 in a Japanese population. Int J Legal Med 2002;116:191-4.

[14] Iida R, Sawazaki K, Ikeda H, Miyamoto T, Tsubota E, Takatsuka H, Masuyama M, Matsuki T, Yasuda T, Kishi K. A novel multiplex PCR system consisting of Y-STRs DYS441, DYS442, DYS443, DYS444 and DYS445. J Forensic Sci 2003;48:1-3.

[15] Ogata Y, Yamaba T, Sawazaki K, Iida R, Tubota E, Takatsuka H, Matsuki T, Yasuda T, Kishi K. Improvement of a multiplex PCR system for DYS441, DYS442, DYS443, DYS444, DYS445, and a population study in 340 Japanese males. Legal Med, in press.

[16] Dong JG, Hou YP, Li YB, Wu J, Tang JP, Ji Q. Allele frequencies of Y-chromosome STR locus DYS445 in a Chinese population. J Forensic Sci $2002 ; 47: 1160$.

[17] Tang JP, Hou YP, Li YB, Wu J, Zhang J, Zhang HJ. Characterization of eight Y-STR loci and haplotypes in a Chinese Han population. Int J Legal Med $2003 ; 117: 263-70$.

[18] Daniels DL, Hall AM, Ballantyne J. SWGDAM developmental validation of a 19-locus Y-STR system for forensic casework. J Forensic Sci 2004 ;49:668-83.

[19] Dai HL, Wang XD, Li YB, Wu J, Zhang J, Zhang HJ, Dong JG, Hou YP. Characterization and haplotype analysis of 10 novel Y-STR loci in Chinese Han population. Forensic Sci Int 2004;145:47-55. 
Figure legends

Fig. 1. A schematic diagram of the $\mathrm{Y}$ chromosome showing the positions of the five Y-STRs.

Fig. 2. Distributions of allele frequencies of DYS441 and DYS442 in Caucasian, African American and Japanese populations. SD: STR diversity. ${ }^{a}$ Hanson EK and Ballantyne J, personal communication.

Fig. 3. Distributions of allele frequencies of DYS443, DYS444 and DYS445 in Caucasian, African American, Japanese and Chinese Han populations. SD: STR diversity. ${ }^{a}$ Hanson EK and Ballantyne J, ref. 10. ${ }^{\text {b, c }}$ Dong JG et al. ref. 16, Tang JP et al. ref. 17 . 


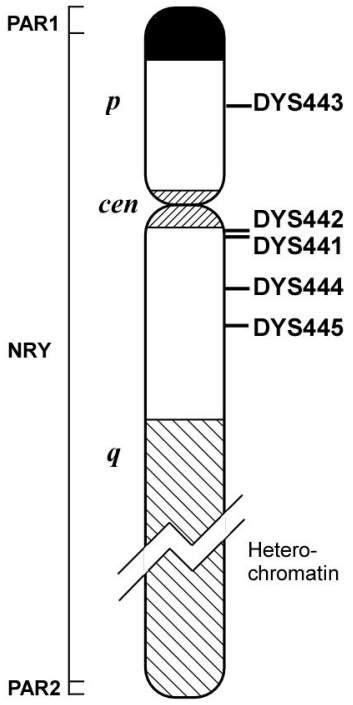


DYS441

acaucasian

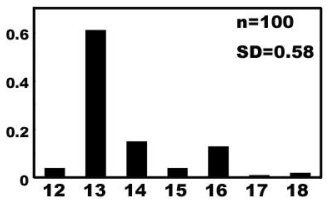

African

American

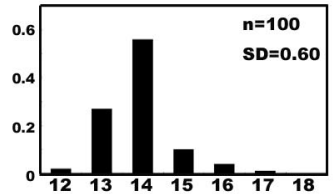

Japanese

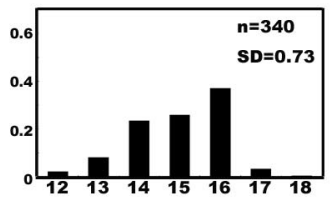

DYS442
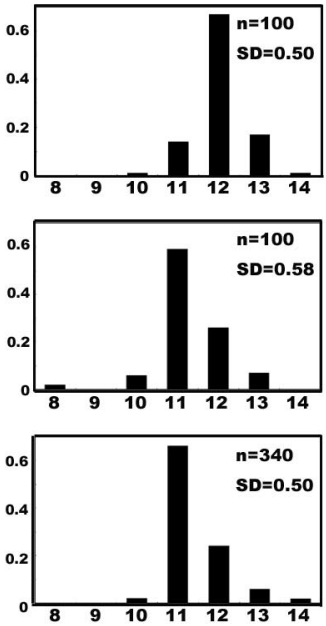


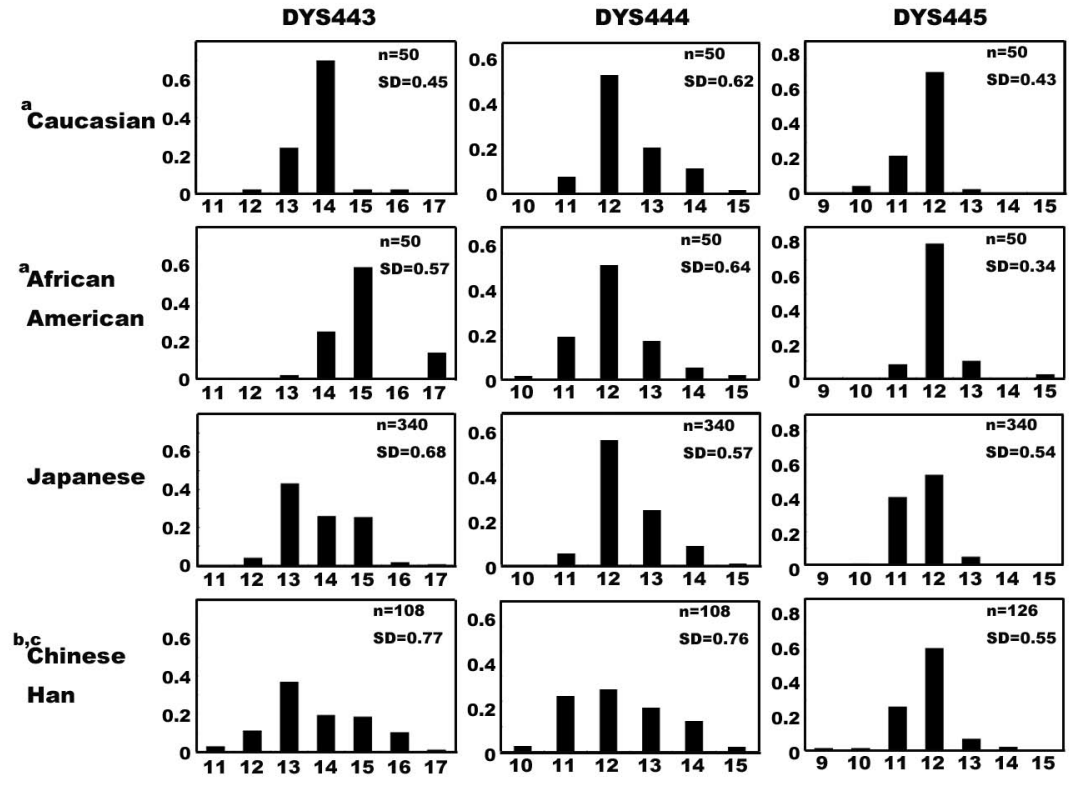

